\title{
Surface Oxidation of Carbon Nanofibres
}

\section{Tijmen G. Ros, Adrianus J. van Dillen, John W. Geus, and Diederik C. Koningsberger*[a]}

\begin{abstract}
Carbon nanofibres of the fishbone and parallel types were surface-oxidised by several methods. The untreated and oxidised fibres were studied with infrared spectroscopy, thermogravimetric analysis and X-ray photoelectron spectroscopy (XPS). Oxidation in a mixture of concentrated nitric and sulfuric acids proved to be the most effective method for creating oxygencontaining surface groups. This treatment results not only in the formation of
\end{abstract}

carboxy and carboxyic anhydride groups, but also in the generation of ether-type oxygen groups between graphitic layers that are puckered at their edges. The IR spectroscopic data clearly show that the formation of oxygen-containing surface groups occurs at

Keywords: carbon - IR spectroscopy • nanostructures • surface analysis - oxidation defect sites on the carbon nanofibres and that oxidation proceeds via carbonyl groups and other oxides to carboxy and carboxyic anhydride groups. Owing to the presence of defects, the two types of fibre have similar surface reactivities. With parallel nanofibres, in contrast to fishbone fibres, the macroscopic structure was severely affected by treatment with $\mathrm{HNO}_{3} / \mathrm{H}_{2} \mathrm{SO}_{4}$. The $\mathrm{HNO}_{3} / \mathrm{H}_{2} \mathrm{SO}_{4}$ treated fibres are highly wettable by water.

\section{Introduction}

Carbon nanofibres (CNFs) that are obtained by catalytic decomposition of carbon-containing gases on small metal particles are promising catalyst support materials for liquidphase reactions. The fibres are mechanically strong and can withstand the forces involved in vigorous agitation of the reaction medium. Furthermore, the skeins of fibres possess a mesoporous macrostructure, which decreases the probability of encountering diffusion limitation in liquid-phase catalytic reactions. The structure of the CNFs can be tuned by changing the growth conditions, and their hydrophobicity can be controlled by surface oxidation. Moreover, carbon nanofibres are very pure. They contain no other types of carbon, such as carbon onions, fullerenes or amorphous carbon, and no heteroatoms, such as sulfur, are incorporated during synthesis. They are chemically inert and can be used in strongly acidic or basic liquids. When grown in a fluidised-bed reactor, carbon nanofibres can be obtained at low cost, so that application as a catalyst support material is feasible. ${ }^{[1]}$ Finally, after deactivation of the catalyst CNFs can be combusted to recover the precious metal component.

[a] Prof. D. C. Koningsberger, Dr. T. G. Ros, Dr. A. J. van Dillen, Prof. J. W. Geus

Department in Inorganic Chemistry and Catalysis

Debye institute, Utrecht University

P.O. box 80083, 3508 TB Utrecht (The Netherlands)

Fax: $(+31) 030-2511027$

E-mail: d.c.koningsberger@chem.uu.nl
To employ carbon nanofibres as catalyst supports it is important to be able to modify their surface, for instance, by the introduction of oxygen-containing surface groups. On oxidation, the hydrophobic fibres become more hydrophilic. Wetting properties are very important in catalyst preparation and use. Furthermore, stronger interaction of the fibres with catalyst precursor complexes can be achieved, and oxygencontaining species can be used as anchoring sites for the immobilisation of larger molecules and metal - ligand systems. The route involving reaction with carboxy groups is attractive. Therefore, knowledge about the nature and amount of oxygen-containing groups on the surface of CNFs, as well as the mechanism of oxidation, is essential for the application of CNFs in catalysis.

Classical carbon materials such as activated carbon and carbon black are well-known support materials in catalysis. Treatment of these types of carbon with oxidising agents in the gas or liquid phase results in the formation of oxidic groups, which can be acidic or basic in nature. ${ }^{[2-4]}$ The oxidation occurs at the edges of the graphitic planes. ${ }^{[2,5,6]}$ The presence of acidic groups makes the carbon surface more hydrophilic and decreases the $\mathrm{pH}$ of the point of zero charge. ${ }^{[3,7]}$ The dispersion of an active metal phase on activated carbon catalysts increases with increasing amount of surface oxygen. ${ }^{[8]}$ The presence of carboxy groups gives rise to cation-exchange properties. ${ }^{[3]}$ Scheme 1 presents several structures of oxygen-containing groups that can be present on the surface of carbon materials. Carboxy groups (a) can form carboxyic anhydrides (b) if they are a short distance apart. Lactonic groups (c) can be present as well. Hydroxy groups 


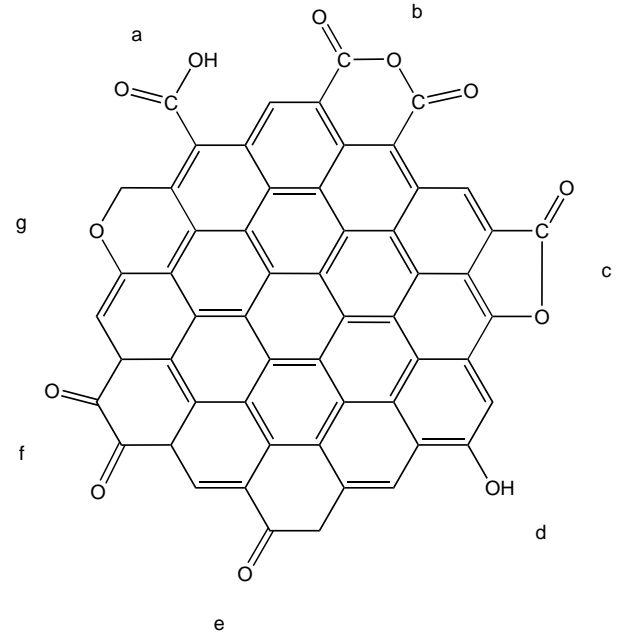

Scheme 1. Different oxygen-containing surface groups on carbon. a) carboxy groups, b) carboxyic anhydride groups, c) lactone groups, d) phenol groups, e) carbonyl groups, f) quinone groups, g) xanthene or ether groups.

(d) at the edge of graphitic planes have phenolic character. The presence of carbonyl groups is very likely. They can be isolated (e) or be arranged in a quinone-like way (f). Finally, xanthene- or ether-type oxygen $(\mathrm{g})$ can substitute for an edge carbon atom.

In contrast to classical carbon materials, the surface oxidation of the relatively new carbon nanotubes and nanofibres has been studied much less. Most of the literature available on the surface oxidation of carbon nanomaterials concerns carbon nanotubes. Crude nanotube material is oxidised for purification purposes: as the nanotubes are much less affected by strong oxidising agents than other forms of carbon, oxidation results in pure nanotubes. ${ }^{[9-12]}$ Similar procedures are used to obtain opened and shortened tubes. ${ }^{[12-17]}$ Strongly oxidised nanotubes and nanofibres can form stable dispersions in water ${ }^{[10,12,18,19]}$ These results show that only strong oxidising agents are effective in creating oxygen-containing groups on the surface of carbon nanomaterials. Oxidation of the parallel carbon nanotubes with gas-phase oxygen only results in the formation of hydroxy and carbonyl groups, whereas liquid-phase oxidation in concentrated acid mixtures also forms carboxy groups. Liquid-phase oxidation can also be better controlled and proceeds more homogeneously than gas-phase treatment. ${ }^{[20]}$ Although some authors ${ }^{[12,21]}$ claim that oxidation only occurs at the open end of nanotubes and nanofibres, most reports in literature state that the oxidation proceeds along the full length of these fibrous materials. ${ }^{[10,19,20,22]}$ The process of oxidation has also been related to defect sites in the graphene layers. ${ }^{[20,22]}$

Much less is known about the oxidation behaviour of carbon nanofibres. Fishbone and parallel CNFs can be distinguished. In fishbone nanofibres the graphitic planes are oriented at an angle to the fibre axis, whereas in parallel fibres the graphitic layers are oriented parallel to the axis. Some studies on the oxidation of parallel CNFs have been reported. ${ }^{[18-21]}$ Hoogenraad et al. used carboxy groups on the surface of parallel fibres for ion-exchange syntheses. ${ }^{[23,24]}$

We have studied the surface oxidation of parallel and fishbone carbon nanofibres. The fibres were subjected to several oxidative treatments and, together with other techniques, studied with IR spectroscopy, thermogravimetric analysis and X-ray photoelectron spectroscopy (XPS). The most effective oxidation method is treatment with a mixture of $\mathrm{HNO}_{3}$ and $\mathrm{H}_{2} \mathrm{SO}_{4}$, which results, among others, in the formation of carboxy groups on the surface of the fibres. Furthermore, subsurface ether-type groups are formed between the graphitic layers. The formation of oxygen-containing surface groups occurs at defect sites on the carbon nanofibres. During the oxidation process carbonyl, phenol and ether groups are formed initially, which are subsequently converted into carboxy, carboxyic anhydride and lactone groups. Only minor differences between parallel and fishbone CNFs were observed.

\section{Results}

Physisorption of $\mathbf{N}_{\mathbf{2}}$ : The $\mathrm{N}_{2}$ physisorption data for the untreated and oxidised carbon nanofibres are presented in Table 1. Untreated fishbone CNFs have a specific surface area of $103 \mathrm{~m}^{2} \mathrm{~g}^{-1}$ and a pore volume of $0.31 \mathrm{mLg}^{-1}$. The average pore diameter is about $12 \mathrm{~nm}$, and no micropores are present.

Table 1. $\mathrm{N}_{2}$-physisorption data of untreated and oxidised carbon nanofibres.

\begin{tabular}{lcccc}
\hline & \multicolumn{3}{c}{ BET surface pore vol. micropore vol. average pore } \\
& area $\left[\mathrm{m}^{2} \mathrm{~g}^{-1}\right]\left[\mathrm{mLg}^{-1}\right]\left[\mathrm{mLg}^{-1}\right]$ & diameter [nm] \\
\hline $\begin{array}{l}\text { Fishbone } \\
\text { untreated }\end{array}$ & 103 & 0.31 & 0.001 & 12 \\
60 min $\mathrm{HNO}_{3}$ & 123 & 0.30 & 0.001 & 10 \\
60 min $\mathrm{HNO}_{3} / \mathrm{H}_{2} \mathrm{SO}_{4}$ & 120 & 0.34 & 0.001 & 11 \\
120 min $\mathrm{KMnO}_{4}-\mathrm{H}^{+}$ & 122 & 0.37 & 0.001 & 12 \\
Parallel & & & & \\
untreated & 158 & 1.16 & 0.004 & 29 \\
30 min $\mathrm{HNO}_{3}$ & 184 & 1.26 & 0.002 & 27 \\
30 min $\mathrm{HNO}_{3} / \mathrm{H}_{2} \mathrm{SO}_{4} 116$ & 0.54 & 0.003 & 19 \\
60 min $500{ }^{\circ} \mathrm{C}$ in air & 180 & 0.87 & 0.012 & 19 \\
\hline
\end{tabular}

Oxidation in acid or potassium permanganate does not change the average pore diameter, and no micropores are formed. However, a slight increase in specific surface area and pore volume is observed. Oxidation with hydrogen peroxide or oxygen did not result in any textural changes.

The untreated parallel CNFs have a specific surface area of $158 \mathrm{~m}^{2} \mathrm{~g}^{-1}$ and a pore volume of $1.16 \mathrm{mLg}^{-1}$. The relatively open macroscopic structure is reflected in a higher average pore diameter of $29 \mathrm{~nm}$, again without any micropores. Oxidation in nitric acid results in a slight increase in surface area and pore volume, comparable to the results obtained with the fishbone CNFs. In contrast, treatment with $\mathrm{HNO}_{3} /$ $\mathrm{H}_{2} \mathrm{SO}_{4}$ leads to a considerable decrease in surface area, pore volume and average pore diameter. However, no micropores are formed. Oxidation in air at $500^{\circ} \mathrm{C}$ also changes the texture of parallel CNFs severely. The surface area is increased, but the pore volume and the average pore diameter are decreased. 
Electron microscopy: Figure 1 shows some scanning electron microscopy (SEM) images of untreated and acid-oxidised fishbone and parallel carbon nanofibres. With fishbone CNFs
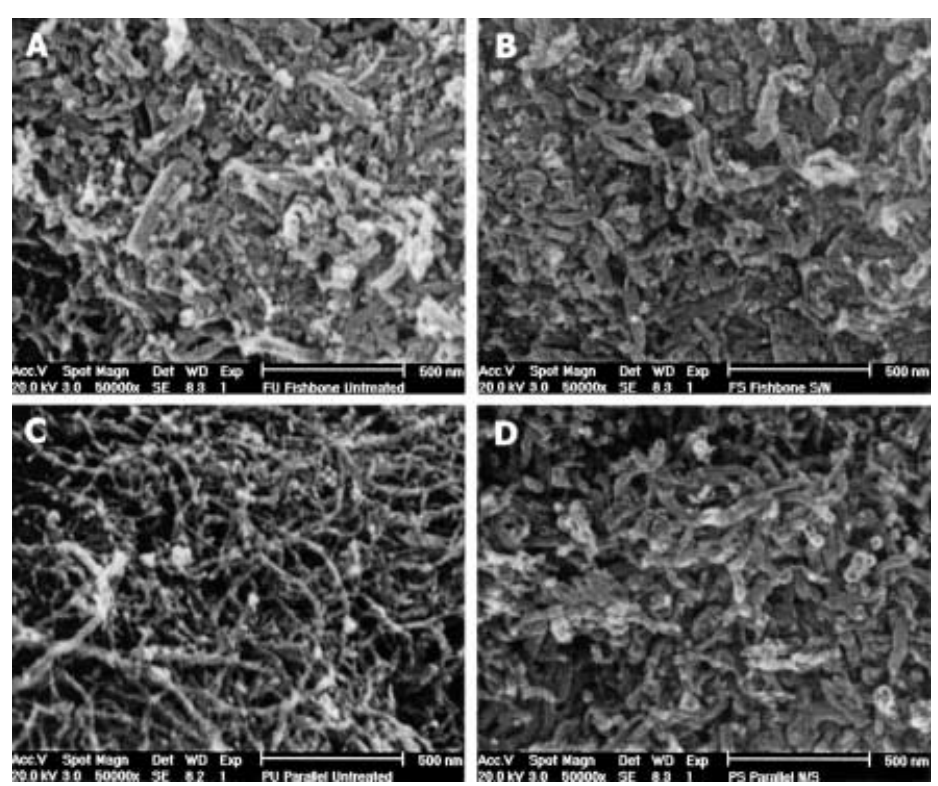

Figure 1. SEM images of carbon nanofibres. A) untreated fishbone; B) fishbone, 60 min $\mathrm{HNO}_{3} / \mathrm{H}_{2} \mathrm{SO}_{4}, \mathrm{C}$ ) untreated parallel, and D) parallel, $30 \mathrm{~min} \mathrm{HNO}_{3} / \mathrm{H}_{2} \mathrm{SO}_{4}$.

no significant change was observed after oxidation in $\mathrm{HNO}_{3} /$ $\mathrm{H}_{2} \mathrm{SO}_{4}$ for $60 \mathrm{~min}$ (Figure $1 \mathrm{~A}$ and $\mathrm{B}$ ). The SEM images of untreated and oxidised $\left(\mathrm{HNO}_{3} / \mathrm{H}_{2} \mathrm{SO}_{4}, 30 \mathrm{~min}\right)$ parallel fibres (Figure 1C and D) show that the macrostructure of these fibres is severely affected by the oxidative treatment: the macrostructure becomes denser.

A study of the fishbone nanofibres by transmission electron microscopy (TEM) did not reveal much difference between untreated and treated $\left(\mathrm{HNO}_{3} / \mathrm{H}_{2} \mathrm{SO}_{4}, 60 \mathrm{~min}\right)$ fibres (images not shown). In both cases, long isolated fibres were found, and the structure of individual fibres remained unchanged. Careful examination of bright- and dark-field micrographs gave the impression that the acid-treated fibres became slightly shorter and less ordered. Some indication of surface roughening was found as well. However, these results are difficult to interpret. Fibre diameters of $15-20 \mathrm{~nm}$ for untreated parallel and 20-90 nm for untreated fishbone CNFs were found.

X-ray diffraction (XRD): The XRD patterns of untreated fishbone CNFs and of fibres that were treated for $30 \mathrm{~min}$ in $\mathrm{HNO}_{3} / \mathrm{H}_{2} \mathrm{SO}_{4}$ are presented in Figure 2. In the pattern of the untreated fibres, several graphite peaks can be distinguished, the strongest of which is the $d(002)$ reflection at $2 \theta=30^{\circ}$. Further peaks can be assigned to $\mathrm{Ni}$ and $\mathrm{Al}_{2} \mathrm{O}_{3}$ originating from the original growth catalyst. The oxidised nanofibres still exhibit all graphite reflections, and the $d(002)$ reflection is not changed in position or width. In addition, nickel reflections are no longer present, and only the alumina reflection at $2 \theta=$ $53^{\circ}$ is still visible after oxidation. Similar results were obtained for the parallel carbon nanofibres (data not shown).

Infrared spectroscopy: The presence of oxygen-containing surface groups on carbon nanofibres was established by IR

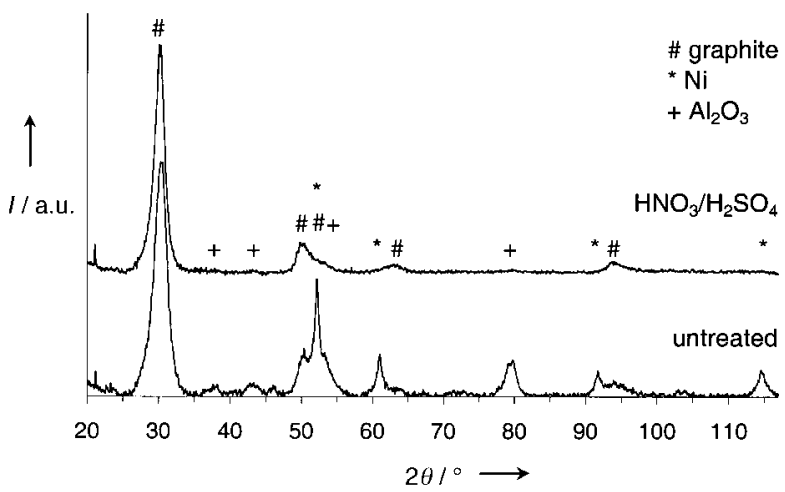

Figure 2. X-ray diffraction patterns of untreated and treated $(30 \mathrm{~min}$ $\mathrm{HNO}_{3} / \mathrm{H}_{2} \mathrm{SO}_{4}$ ) fishbone carbon nanofibres.

spectroscopy. To allow comparison, transmission levels of all spectra were kept approximately the same. It was ascertained that, within the transmission window used, the intensity of the bands did not depend upon the transmission level of the spectra. Figure 3 displays the $2000-800 \mathrm{~cm}^{-1}$ region of the IR

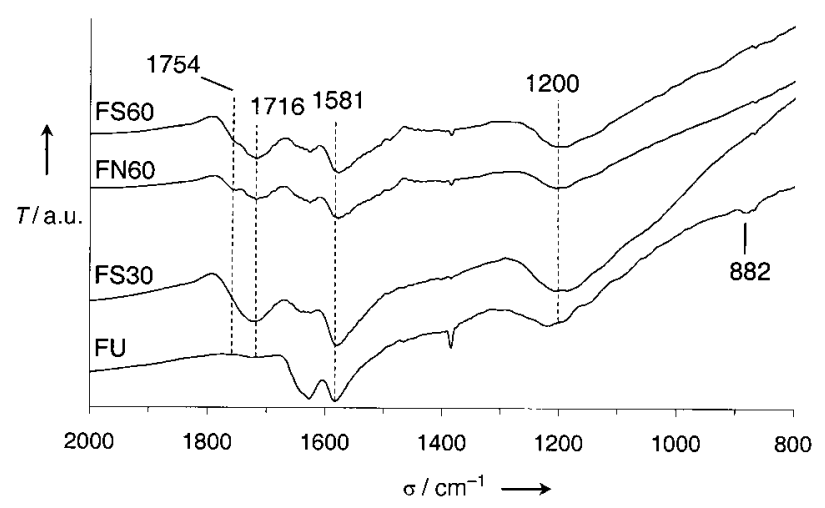

Figure 3. IR spectra of untreated (FU), $30 \mathrm{~min} \mathrm{HNO}_{3} / \mathrm{H}_{2} \mathrm{SO}_{4^{-}}(\mathrm{FS} 30)$, $60 \mathrm{~min} \mathrm{HNO}_{3}-(\mathrm{FN} 60)$, and 60 min $\mathrm{HNO}_{3} / \mathrm{H}_{2} \mathrm{SO}_{4}$-oxidised (FS60) fishbone carbon nanofibres.

spectra of untreated and oxidised fishbone carbon nanofibres. All band assignments are summarised in Table 2, and all changes observed in the IR spectra after the different oxidative treatments are summarised in Table 3. The assignment of the bands of the untreated fibres is discussed

Table 2. Assignments of infrared absorptions found for untreated and oxidised fishbone and parallel carbon nanofibres.

\begin{tabular}{lll}
\hline $\begin{array}{l}\text { Wavenumber } \\
{\left[\mathrm{cm}^{-1}\right]}\end{array}$ & Assignment & References \\
\hline 3012 & aromatic $\mathrm{C}-\mathrm{H}$ stretching & {$[29]$} \\
2947 & $\mathrm{CH}_{2} / \mathrm{CH}_{3}$ stretching & {$[29]$} \\
$2917-2912$ & $\mathrm{CH}_{2} / \mathrm{CH}_{3}$ stretching & {$[29]$} \\
$2846-2841$ & $\mathrm{CH}_{2} / \mathrm{CH}_{3}$ stretching & {$[29]$} \\
1754 & $\mathrm{C}=\mathrm{O}$ stretching anhydride \& lactone & {$[3,19,26,32]$} \\
$1725-1714$ & $\mathrm{C}=\mathrm{O}$ stretching carbonyl \& carboxy & {$[19,26,29,31]$} \\
1633 & adsorbed water & {$[19,26]$} \\
$1581-1578$ & aromatic ring stretching & {$[26,29,30]$} \\
1454 & $\mathrm{CH} / \mathrm{CH}$ bending & {$[29,33]$} \\
1384 & nitrate & {$[27,28]$} \\
$1217-1188$ & $\mathrm{C}-\mathrm{C}$ stretching & {$[26,29]$} \\
$882-872$ & isolated aromatic $\mathrm{C}-\mathrm{H}$ out-of-plane bending & {$[29]$} \\
\hline
\end{tabular}


Table 3. Changes in the IR spectra of fishbone and parallel carbon nanofibres after the different oxidative treatments. ${ }^{[a]}$

\begin{tabular}{|c|c|}
\hline Treatment & Observations \\
\hline \multicolumn{2}{|l|}{ Fishbone } \\
\hline $60 \min \mathrm{HNO}_{3}$ & $+1716,1754 ;-882$ \\
\hline $30 \mathrm{~min} \mathrm{HNO}_{3} / \mathrm{H}_{2} \mathrm{SO}_{4}$ & $+1716 ;-882 ;$ i 1200 \\
\hline $60 \mathrm{~min} \mathrm{HNO}_{3} / \mathrm{H}_{2} \mathrm{SO}_{4}$ & $+1716,1754 ;-882 ; \mathrm{d} 2947,2912,2841$ \\
\hline $\mathrm{KMnO}_{4}-\mathrm{H}^{+}$ & $+1716 ;-882 ;$ i 1200 \\
\hline $20 \% \mathrm{O}_{2} / \mathrm{He} 300^{\circ} \mathrm{C}$ & no change \\
\hline $\mathrm{H}_{2} \mathrm{O}_{2}$ & +1724 \\
\hline \multicolumn{2}{|l|}{ Parallel } \\
\hline $30 \mathrm{~min} \mathrm{HNO}_{3}$ & + 1714; - 872, 1454; i 1200; d 3012, 2947, 2917, 2846 \\
\hline $\begin{array}{l}30 \mathrm{~min} \mathrm{HNO}_{3} / \mathrm{H}_{2} \mathrm{SO}_{4} \\
\text { air } 500^{\circ} \mathrm{C}\end{array}$ & $\begin{array}{l}+1714 ;-872,1454 ; \text { i } 1200 ;-3012,2947,2917,2846 \\
+1725 ; \text { s } 872 ; \text { i } 1200\end{array}$ \\
\hline
\end{tabular}

[a] + band appears, - band disappears, i intensity band increases, $d$ intensity band decreases, $\mathrm{s}$ band shifts.

elsewhere. ${ }^{[25]}$ The absorptions at 1633 and $1384 \mathrm{~cm}^{-1}$ are due to water and nitrate, respectively, adsorbed on the $\mathrm{KBr}$ and can be disregarded. ${ }^{[19,26-28]}$ The minimum at $1581 \mathrm{~cm}^{-1}$ originates from an aromatic ring vibration, while the broad band at $1200 \mathrm{~cm}^{-1}$ is attributed to the $\mathrm{C}-\mathrm{C}$ stretching vibration. ${ }^{[26,29,30]}$ The peak at $882 \mathrm{~cm}^{-1}$ is ascribed to the isolated aromatic $\mathrm{C}-\mathrm{H}$ out-of-plane bending mode. ${ }^{[29]}$

After oxidation in acid for $60 \mathrm{~min}$, two additional bands appear in the spectrum of the fibres at 1716 and $1754 \mathrm{~cm}^{-1}$ (Figure 3). The peak at $1716 \mathrm{~cm}^{-1}$ can be assigned to the $\mathrm{C}=\mathrm{O}$ stretching vibration of carboxy or carbonyl groups, while that at $1754 \mathrm{~cm}^{-1}$ is associated with carboxyic anhydride or lactone groups. $^{[3,19,26,29,31,32]}$ The aromatic $\mathrm{C}-\mathrm{H}$ vibration at $882 \mathrm{~cm}^{-1}$ disappears upon oxidation. The intensity of the $\mathrm{C}=\mathrm{O}$ bands is higher for the $\mathrm{HNO}_{3} / \mathrm{H}_{2} \mathrm{SO}_{4}$-oxidised fibres than for the $\mathrm{HNO}_{3}$-treated CNFs. Fibres treated with $\mathrm{HNO}_{3} / \mathrm{H}_{2} \mathrm{SO}_{4}$ for only $30 \mathrm{~min}$, do not show the band at $1754 \mathrm{~cm}^{-1}$, although it might be obscured by the broad absorption at $1716 \mathrm{~cm}^{-1}$. Moreover, the intensity of the $1200 \mathrm{~cm}^{-1}$ band is significantly enhanced. In this region $\mathrm{C}-\mathrm{O}$ stretching and $\mathrm{O}-\mathrm{H}$ bending vibrations occur as well. ${ }^{[29]}$ Figure 4 shows the $3200-$ $2700 \mathrm{~cm}^{-1}$ region of the untreated and the oxidised $\left(\mathrm{HNO}_{3} /\right.$

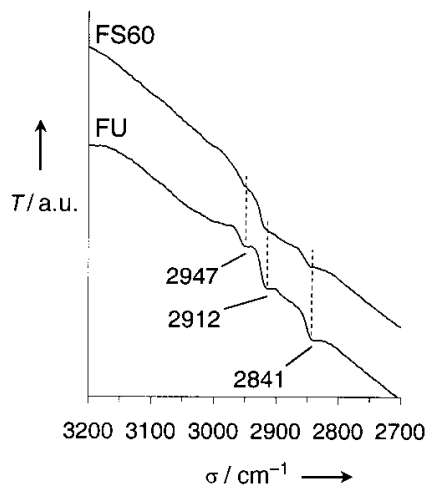

Figure 4. IR spectra of untreated (FU) and 60 min $\mathrm{HNO}_{3} / \mathrm{H}_{2} \mathrm{SO}_{4}$-oxidised (FS60) fishbone carbon nanofibres.

$\mathrm{H}_{2} \mathrm{SO}_{4}, 60 \mathrm{~min}$ ) fishbone fibres. The bands at 2947, 2912, and $2841 \mathrm{~cm}^{-1}$ arise from $\mathrm{CH}_{2} / \mathrm{CH}_{3}$ stretching vibrations. ${ }^{[25,29]}$ After oxidation, the intensity of the $\mathrm{CH}_{2} / \mathrm{CH}_{3}$ minima of the treated sample is decreased considerably.
The spectrum of the fibres treated in oxygen at $300^{\circ} \mathrm{C}$ is identical to that of untreated fibres. $\mathrm{H}_{2} \mathrm{O}_{2}$-oxidised fibres exhibit a weak minimum at $1724 \mathrm{~cm}^{-1}$. Oxidation in $\mathrm{KMnO}_{4} /$ $\mathrm{H}^{+}$results in a spectrum very similar to that of fishbone nanofibres treated with $\mathrm{HNO}_{3} / \mathrm{H}_{2} \mathrm{SO}_{4}$ for 30 min (spectra not shown).

Figures 5 and 6 show the infrared spectra for the oxidation of parallel fibres in $\mathrm{HNO}_{3}$ and $\mathrm{HNO}_{3} / \mathrm{H}_{2} \mathrm{SO}_{4}$ for $30 \mathrm{~min}$. The band at $1454 \mathrm{~cm}^{-1}$ in the spectrum of the untreated fibres

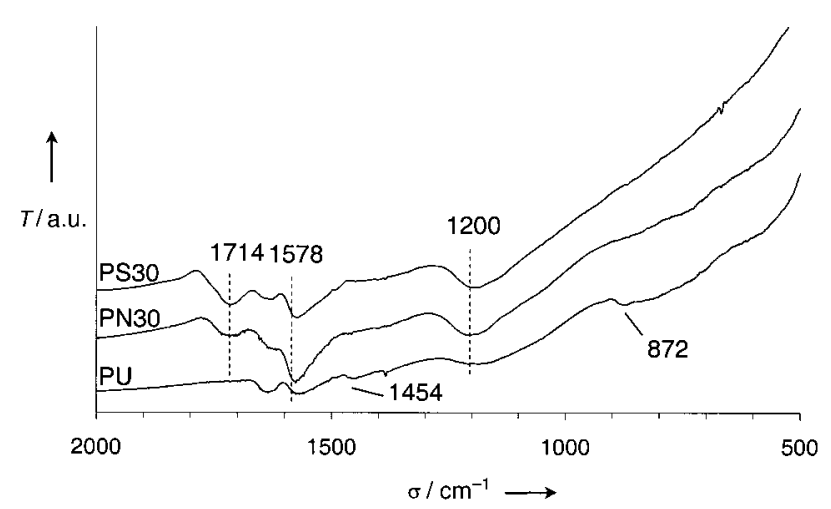

Figure 5. IR spectra of untreated (PU), 30 min $\mathrm{HNO}_{3^{-}}$(PN30), and $30 \mathrm{~min}$ $\mathrm{HNO}_{3} / \mathrm{H}_{2} \mathrm{SO}_{4}$-oxidised (PS30) parallel carbon nanofibres.

is attributed to $\mathrm{CH}_{2} / \mathrm{CH}_{3}$ bending vibrations. ${ }^{[25,29,33]}$ Upon oxidation in acid, the appearance of the carbonyl/carboxy band at $1714 \mathrm{~cm}^{-1}$ is accompanied by an increase in intensity of the $1200 \mathrm{~cm}^{-1}$ absorption due to $\mathrm{CO}$ and $\mathrm{OH}$ groups. The anhydride/lactone band at about $1750 \mathrm{~cm}^{-1}$ is missing, although it might be obscured by the asymmetric $1714 \mathrm{~cm}^{-1}$

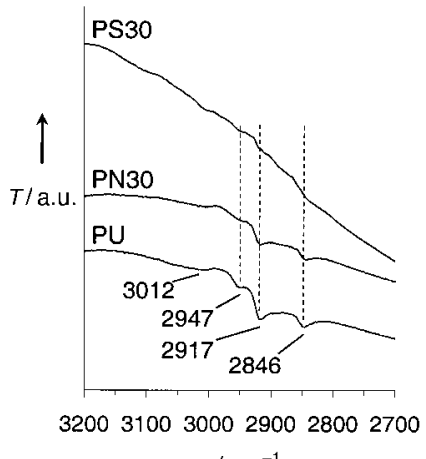

$\sigma / \mathrm{cm}^{-1} \longrightarrow$

Figure 6. IR spectra of untreated (PU), $30 \mathrm{~min} \mathrm{HNO}_{3^{-}}(\mathrm{PN} 30)$, and $30 \mathrm{~min}$ $\mathrm{HNO}_{3} / \mathrm{H}_{2} \mathrm{SO}_{4}$-oxidised (PS30) parallel carbon nanofibres.

band of the $\mathrm{HNO}_{3} / \mathrm{H}_{2} \mathrm{SO}_{4}$-treated fibres. Both the $\mathrm{CH}_{2} / \mathrm{CH}_{3}$ peak at $1454 \mathrm{~cm}^{-1}$ and the aromatic $\mathrm{C}-\mathrm{H}$ vibration at $872 \mathrm{~cm}^{-1}$ disappear upon oxidation. The intensity of the $\mathrm{CH}_{2} / \mathrm{CH}_{3}$ stretching minima and the aromatic $\mathrm{C}-\mathrm{H}$ stretching vibration at $3012 \mathrm{~cm}^{-1}$ in the $3200-2700 \mathrm{~cm}^{-1}$ region clearly show a trend (Figure 6). Whereas $\mathrm{HNO}_{3}$ treatment diminishes the intensity of all bands significantly, for the $\mathrm{HNO}_{3} / \mathrm{H}_{2} \mathrm{SO}_{4}{ }^{-}$ treated fibres these absorptions can no longer be observed.

Air-oxidised parallel fibres show a band at $1725 \mathrm{~cm}^{-1}$ (spectrum not shown). The $1454 \mathrm{~cm}^{-1}$ peak, however, remains 
present and the $872 \mathrm{~cm}^{-1}$ band shifts to $834 \mathrm{~cm}^{-1}$. The intensity of the $1200 \mathrm{~cm}^{-1}$ absorption increases significantly.

Thermogravimetric analysis (TGA) in an inert environment: TGA-MS provides additional information on the oxygencontaining surface groups that were formed on the carbon nanofibres. Figure 7 shows a typical TGA-MS profile (both

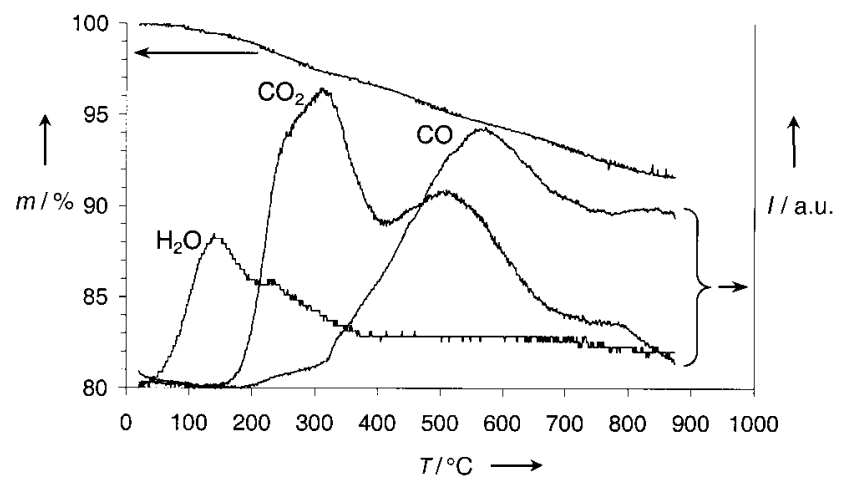

Figure 7. Typical TGA-MS pattern in Ar for acid-oxidised carbon nanofibres (fishbone, $60 \mathrm{~min} \mathrm{HNO}_{3} / \mathrm{H}_{2} \mathrm{SO}_{4}$ ).

for fishbone and parallel fibres) for $\mathrm{KMnO}_{4} / \mathrm{H}^{+}$- or acidoxidised carbon nanofibres (fishbone: $\mathrm{HNO}_{3} / \mathrm{H}_{2} \mathrm{SO}_{4}, 60 \mathrm{~min}$ ). A weight loss of more than $8 \%$ is accompanied by the release of $\mathrm{H}_{2} \mathrm{O}, \mathrm{CO}$ and $\mathrm{CO}_{2}$. The weight loss at $850{ }^{\circ} \mathrm{C}$ was used for further analysis. This value could be reproduced within $2-4 \%$ of the absolute value. Owing to the limitations of the experimental setup, the interpretation of the evolved gas peaks can only be qualitative. Moreover, although the shape of the peaks remained the same in control experiments, the temperature values for the onset and the maximum of the $\mathrm{CO}$ and $\mathrm{CO}_{2}$ peaks varied. These values, therefore, must also be considered qualitatively.

Figure 7 shows that on heating in argon fishbone fibres treated for $60 \mathrm{~min}$ with $\mathrm{HNO}_{3} / \mathrm{H}_{2} \mathrm{SO}_{4}$ release water up to about $375^{\circ} \mathrm{C}$, with a peak at about $150^{\circ} \mathrm{C}$ and a shoulder at $230^{\circ} \mathrm{C}$. The $\mathrm{CO}_{2}$ profile displays two peaks at about 300 and $500^{\circ} \mathrm{C}$. A shoulder above $750^{\circ} \mathrm{C}$ can be distinguished as well. The CO-liberation pattern exhibits one broad peak with a maximum at around $600^{\circ} \mathrm{C}$ and a shoulder at higher temperatures. The TGA-MS peak assignments are summarised in Table 4. The water peak at around $150^{\circ} \mathrm{C}$ can be ascribed to physisorbed water. ${ }^{[7]}$ The $\mathrm{H}_{2} \mathrm{O}$ shoulder at $230^{\circ} \mathrm{C}$ may provide

Table 4. Peak assignments of the TGA-MS profiles in Ar.

\begin{tabular}{lll}
\hline Peak & Assignment & References \\
\hline $\mathrm{H}_{2} \mathrm{O}$ & & \\
$150{ }^{\circ} \mathrm{C}$ & physisorbed water & {$[7]$} \\
$230{ }^{\circ} \mathrm{C}$ & formation of anhydrides during experiment & {$\left[{ }^{\circ}\right]$} \\
$>300^{\circ} \mathrm{C}$ & phenols & {$[35]$} \\
$\mathrm{CO}_{2}$ & & \\
$300^{\circ} \mathrm{C}$ & carboxyic acids & {$[2,3,26,32,34]$} \\
$500^{\circ} \mathrm{C}$ & carboxyic anhydrides & {$[3,7,32]$} \\
$>750{ }^{\circ} \mathrm{C}$ & lactones & {$[32]$} \\
$\mathrm{CO}$ & & {$[7,32]$} \\
$600^{\circ} \mathrm{C}$ & phenols, carbonyls, quinones, ethers & \\
\hline
\end{tabular}

evidence for the formation of carboxyic anhydrides from adjacent carboxy groups during the TGA experiment. ${ }^{[7]}$ The first $\mathrm{CO}_{2}$ peak can undoubtedly be attributed to carboxyic acid groups. ${ }^{[2,3,26,32,34]}$ Anhydrides evolve $\mathrm{CO}_{2}$ and $\mathrm{CO}$ at higher temperatures. ${ }^{[3,7,32]}$ Hence, the $\mathrm{CO}_{2}$ evolution at higher temperatures probably originates from anhydrides. The $\mathrm{CO}_{2}$ shoulder above $750^{\circ} \mathrm{C}$ may be tentatively assigned to lactonic groups. ${ }^{[32]}$ For the $\mathrm{CO}$ evolution profile, assignment of specific groups to peaks or shoulders is difficult. In principle, $\mathrm{CO}$ could originate from phenol, carbonyl, quinone and ether groups. ${ }^{[7,32]}$

Fishbone fibres that were treated with $\mathrm{HNO}_{3} / \mathrm{H}_{2} \mathrm{SO}_{4}$ for only $30 \mathrm{~min}$ have a different TGA-MS profile (Figure 8). A second $\mathrm{H}_{2} \mathrm{O}$ peak above $300^{\circ} \mathrm{C}$ appears, which can be ascribed

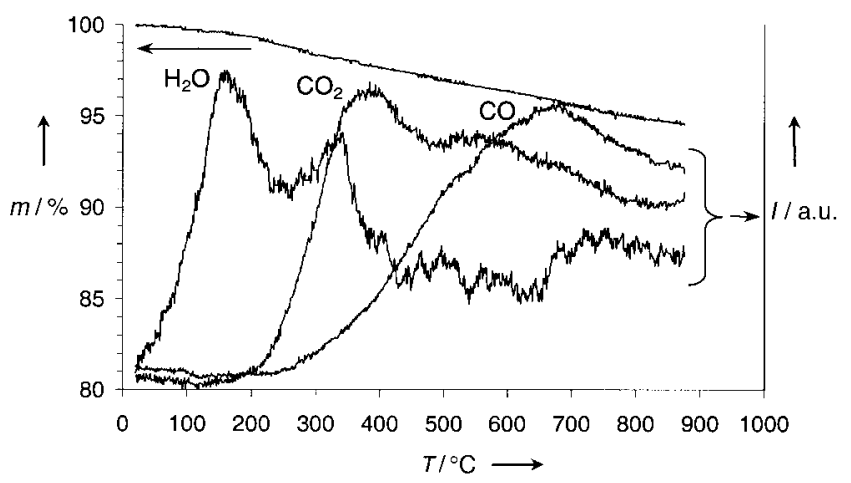

Figure 8. TGA-MS pattern in $\mathrm{Ar}$ of $30 \mathrm{~min} \mathrm{HNO}_{3} / \mathrm{H}_{2} \mathrm{SO}_{4}$-oxidised fishbone carbon nanofibres.

to phenolic groups. ${ }^{[35]}$ Furthermore, the high-temperature $\mathrm{CO}_{2}$ peak, attributed to carboxyic anhydrides, is merely a shoulder. Finally, the $\mathrm{CO}$ evolution pattern has its maximum at a significantly higher temperature $\left(\mathrm{ca} .700^{\circ} \mathrm{C}\right)$.

Untreated carbon nanofibres do not evolve $\mathrm{H}_{2} \mathrm{O}$. Both types of untreated fibre exhibit a broad $\mathrm{CO}$ band, but only untreated fishbone fibres lose $\mathrm{CO}_{2}$ above $400{ }^{\circ} \mathrm{C}$. The evolvedgas patterns for the gas-phase-treated fibres $\left(72 \mathrm{~h}\right.$ at $300^{\circ} \mathrm{C}$ in $20 \% \mathrm{O}_{2} / \mathrm{He}$ for the fishbone fibres, and $1 \mathrm{~h}$ at $500^{\circ} \mathrm{C}$ in air for the parallel CNFs) are similar to those of the untreated fibres, except that treated parallel nanofibres also show loss of $\mathrm{CO}_{2}$ above $400^{\circ} \mathrm{C}$. Finally, the $\mathrm{CO}_{2}$ evolution profile of the $\mathrm{H}_{2} \mathrm{O}_{2-}$ treated fishbone carbon nanofibres exhibits a peak at around $300^{\circ} \mathrm{C}$, indicative of carboxy groups. However, no $\mathrm{H}_{2} \mathrm{O}$ is evolved.

Table 5 lists the weight losses at $850^{\circ} \mathrm{C}$ after correction for the loss of physisorbed water. Figure 7 shows that the peak for physisorbed water is relatively isolated. Evolution of $\mathrm{CO}_{2}$ starts well after the $\mathrm{H}_{2} \mathrm{O}$ peak maximum. Therefore, the weight loss due to physisorbed water can be subtracted from the total weight loss at $850^{\circ} \mathrm{C}$. It is apparent that, except for oxygen treatment at $300^{\circ} \mathrm{C}$, the weight loss of the oxidised samples is considerably higher than that of the untreated fibres.

X-ray photoelectron spectroscopy (XPS): The surface oxidation of the fishbone CNFs was also studied by measuring the $\mathrm{C}_{1 \mathrm{~s}}$ and $\mathrm{O}_{1 \mathrm{~s}}$ XPS peaks of untreated and oxidised fibres 
Table 5. TGA-MS weight losses in $\mathrm{Ar}$ at $850^{\circ} \mathrm{C}$ after correction for physisorbed water for untreated and oxidised carbon nanofibres.

\begin{tabular}{ll}
\hline & Weight loss at $850^{\circ} \mathrm{C}$ after corr. phys. $\mathrm{H}_{2} \mathrm{O}(\%)$ \\
\hline Fishbone & 1.4 \\
untreated & 1.1 \\
$72 \mathrm{~h} 300{ }^{\circ} \mathrm{C} \mathrm{O}_{2} / \mathrm{He}$ & 2.0 \\
$120 \mathrm{~min} \mathrm{H}_{2} \mathrm{O}_{2}$ & 4.2 \\
120 min $\mathrm{KMnO}_{4}-\mathrm{H}^{+}$ & 3.9 \\
60 min $\mathrm{HNO}_{3}$ & 4.3 \\
30 min $\mathrm{HNO}_{3} / \mathrm{H}_{2} \mathrm{SO}_{4}$ & 7.0 \\
60 min $\mathrm{HNO}_{3} / \mathrm{H}_{2} \mathrm{SO}_{4}$ & \\
Parallel & 2.5 \\
untreated & 6.4 \\
60 min $500{ }^{\circ} \mathrm{C}$ in air & 4.5 \\
30 min $\mathrm{HNO}_{3}$ & 4.9 \\
30 min $\mathrm{HNO}_{3} / \mathrm{H}_{2} \mathrm{SO}_{4}$ &
\end{tabular}

$\left(\mathrm{HNO}_{3} / \mathrm{H}_{2} \mathrm{SO}_{4}, 60 \mathrm{~min}\right)$. The measurements were carried out on the same sample before and after in situ evacuation at $150^{\circ} \mathrm{C}$ for $1 \mathrm{~h}$ to remove physisorbed water. Upon oxidation, no change in the shape of the $\mathrm{C}_{1 \mathrm{~s}}$ peak was observed, but the ratio of the areas of the $\mathrm{O}_{1 \mathrm{~s}}$ and $\mathrm{C}_{1 \mathrm{~s}}$ peaks changed (Table 6). The untreated fibres already contain a considerable amount

Table 6. O/C ratios of untreated and 60 min $\mathrm{HNO}_{3} / \mathrm{H}_{2} \mathrm{SO}_{4}$-oxidised fishbone carbon nanofibres obtained by XPS. Samples were measured either without further pre-treatment or after an in situ evacuation at $150{ }^{\circ} \mathrm{C}$ for one hour.

\begin{tabular}{ll}
\hline & $\mathrm{O}_{1 \mathrm{~s}} / \mathrm{C}_{1 \mathrm{~s}}$ ratio \\
\hline $\begin{array}{l}\text { No pre-treatment } \\
\text { untreated }\end{array}$ & 0.22 \\
60 min $\mathrm{HNO}_{3} / \mathrm{H}_{2} \mathrm{SO}_{4}$ & 0.36 \\
$1 \mathrm{~h}$ vacuum $150^{\circ} \mathrm{C}$ & \\
untreated & 0.30 \\
60 min $\mathrm{HNO}_{3} / \mathrm{H}_{2} \mathrm{SO}_{4}$ & 0.46 \\
\hline
\end{tabular}

of oxygen at the surface. After oxidation in $\mathrm{HNO}_{3} / \mathrm{H}_{2} \mathrm{SO}_{4}$ the $\mathrm{O} / \mathrm{C}$ ratio increases by about $60 \%$, independent of the treatment before the XPS measurement.

Thermogravimetric analysis in an oxidizing environment: Thermogravimetric analysis was performed in $20 \% \mathrm{O}_{2} / \mathrm{Ar}$. These experiments were carried out to obtain more knowledge on the crystallinity of the fibres (a lower crystallinity results in a lower onset temperature of bulk oxidation) and the effect of surface oxidation on the bulk oxidation of the CNFs. The results for untreated fishbone and parallel and surface-oxidised $\left(\mathrm{HNO}_{3} / \mathrm{H}_{2} \mathrm{SO}_{4}, 60 \mathrm{~min}\right)$ fishbone carbon nanofibres are shown in Figure 9. The onset of bulk oxidation lies at about $450{ }^{\circ} \mathrm{C}$ for both the untreated parallel and fishbone CNFs. The loss of weight recorded below this temperature is also observed in TGA in pure argon and is therefore not due to bulk oxidation of the fibres. The maximum rate of oxidation occurs at a much lower temperature for the parallel fibres than for the fishbone CNFs. The onset temperature of bulk oxidation for the surface-oxidised fishbone fibres is about $530^{\circ} \mathrm{C}$. The weight loss detected

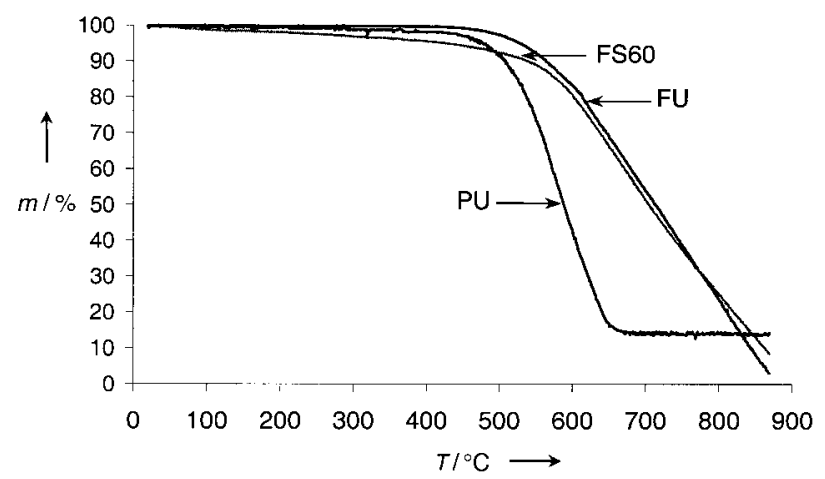

Figure 9. TGA profiles in $20 \% \mathrm{O}_{2} / \mathrm{Ar}$ of untreated parallel (PU), untreated fishbone (FU), and $60 \mathrm{~min} \mathrm{HNO}_{3} / \mathrm{H}_{2} \mathrm{SO}_{4}$-oxidised fishbone (FS60) carbon nanofibres.

below this temperature originates from the decomposition of surface oxides (see above). Finally, above about $600^{\circ} \mathrm{C}$, the oxidation curves for the untreated and surface oxidised fishbone CNFs are identical.

Hydrophobicity: To roughly assess the hydrophobicity of the untreated and acid-oxidised fishbone carbon nanofibres, ground samples of $1 \mathrm{mg}$ were ultrasonically dispersed in $5 \mathrm{~mL}$ of water/hexane (1/1) for $30 \mathrm{~min}$. The CNFs were first wetted with water or hexane. The results are shown in Figure 10. The upper layer is the hexane layer. Most of the untreated CNFs are situated at the water/hexane interface,
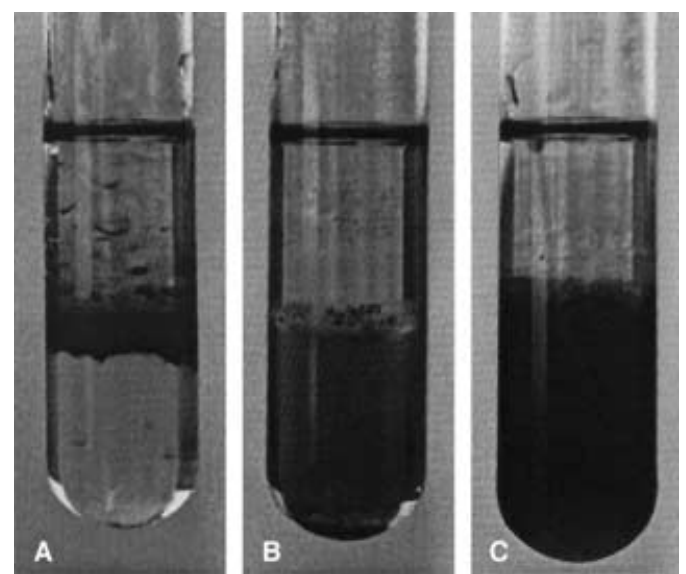

Figure 10. Fishbone carbon nanofibres dispersed in $\mathrm{H}_{2} \mathrm{O}$ /hexane. A) untreated, B) $60 \mathrm{~min} \mathrm{HNO}_{3}$, and C) $60 \mathrm{~min} \mathrm{HNO}_{3} / \mathrm{H}_{2} \mathrm{SO}_{4}$. Hexane is the upper layer.

and some can be detected in the hexane layer (Figure $10 \mathrm{~A}$ ). The fibres oxidised for $60 \mathrm{~min}$ in $\mathrm{HNO}_{3} / \mathrm{H}_{2} \mathrm{SO}_{4}$ are welldispersed in the water layer (Figure $10 \mathrm{C}$ ), which is no longer penetrated by light. For the fibres treated for $60 \mathrm{~min}$ in $\mathrm{HNO}_{3}$, however, the results depend on the liquid the fibres were first wetted with. When these CNFs are first wetted with water, they disperse poorly in the water layer and form larger aggregates that are also found at the bottom of the test tube (Figure 10B). When the fibres are first wetted with hexane, they show only affinity for the water/hexane interface, comparable to the untreated fibres. 


\section{Discussion}

Macrostructure: Oxidation of fishbone carbon nanofibres in acid or $\mathrm{KMnO}_{4} / \mathrm{H}^{+}$leads to a slight increase in specific surface area and pore volume. The weight fraction of the original $\mathrm{Ni}$ / $\mathrm{Al}_{2} \mathrm{O}_{3}$ growth catalyst in the untreated fibres is only about $4 \%$. Therefore, changes in surface area and pore volume cannot be attributed to removal of the growth catalyst on oxidation. As no micropores are present, the measured surface area can be regarded as the external surface area of the fibres. Accordingly, the pore volume is the space between the fibres. Apparently, on oxidation in $\mathrm{HNO}_{3} / \mathrm{H}_{2} \mathrm{SO}_{4}$ or $\mathrm{KMnO}_{4} / \mathrm{H}^{+}$, the macrostructure of this type of fibre becomes somewhat less dense, and a slightly higher pore volume results. Surface roughening of the fibres by oxidation can explain the increase in surface area. Another explanation could be a difference in affinity of $\mathrm{N}_{2}$ for untreated and oxidised fibres. The changes in macrostructure are probably small, as they are not observable with SEM.

For the parallel fibres, oxidation in $\mathrm{HNO}_{3} / \mathrm{H}_{2} \mathrm{SO}_{4}$ or air results in considerable changes in the macrostructure. Treatment in the mixture of acids probably breaks or completely removes some fibres, and this induces a collapse of the macroscopic structure. The decrease in surface area, pore volume and average pore diameter might suggest that the thinner fibres are preferentially removed. After oxidation in air the macroscopic structure collapses as well, and this leads to a decrease in the pore volume. An enhancement of surface roughness probably causes the increase in surface area. This is supported by the appearance of some micropores after gasphase oxidation. The $\mathrm{N}_{2}$ physisorption data are supported by the SEM data, which show a change in macrostructure only for the parallel fibres. Furthermore, the SEM images of untreated parallel fibres and fibres treated for $30 \mathrm{~min}$ in $\mathrm{HNO}_{3} / \mathrm{H}_{2} \mathrm{SO}_{4}$ suggest that on oxidation in the acid mixture thinner fibres are indeed removed. The diameter of the fibres after oxidation in $\mathrm{HNO}_{3} / \mathrm{H}_{2} \mathrm{SO}_{4}$ seems to be larger on average than before oxidation.

From the BET surface areas, average fibre diameters can be calculated by assuming that the fibres have the same density as graphite $\left(2.25 \mathrm{~g} \mathrm{~cm}^{-3}\right){ }^{[36]}$ Fenelonov et al. ${ }^{[37]}$ found that the density of fishbone fibres is only slightly lower than that of graphite. For the untreated fishbone CNFs an average fibre diameter of $17 \mathrm{~nm}$ was thus calculated, and for untreated parallel fibres a value of $11 \mathrm{~nm}$ was obtained. The values observed with TEM, however, are much larger. The diameter of the fishbone fibres varies between 20 and $90 \mathrm{~nm}$, and that of parallel fibres ranges from 15 to $20 \mathrm{~nm}$. These differences can be explained by assuming that the fibres have a considerable surface roughness. This explanation is supported by Shaikhutdinov, ${ }^{[38]}$ who performed scanning tunnelling microscopy (STM) experiments on fishbone CNFs grown from methane over an $\mathrm{Ni} / \mathrm{Al}_{2} \mathrm{O}_{3}$ catalyst. He found substantial differences in height on the surface of the fibres and calculated the ratio of the measured topographical surface area and the geometrical area of a corresponding reference plane. The values of 4.2 and 4.7 that were obtained indicate a major enhancement of the surface area relative to that of fibres with smooth surfaces. Considering these results, it is likely that the surfaces of the fibres used in this study are also rough. We can also conclude that the surface roughness of the fishbone CNFs is appreciably higher than that of the parallel fibres, as the difference between the diameters from $\mathrm{N}_{2}$ physisorption and TEM is larger. This is reasonable, given the difference in orientation of the graphitic planes in the two types of fibre. Upon oxidation, the surface roughness can be further enhanced.

In conclusion, the texture of fishbone carbon nanofibres was not significantly affected by any of the oxidation methods. With parallel CNFs, on the other hand, only treatment in nitric acid left the macroscopic structure intact. $\mathrm{HNO}_{3} / \mathrm{H}_{2} \mathrm{SO}_{4}$ or air at $500{ }^{\circ} \mathrm{C}$ changed the texture drastically. Furthermore, we conclude that the surface of the untreated fibres is considerably roughened.

Graphitic structure: To establish whether the graphitic structure of the carbon nanofibres is affected by oxidation, XRD and TEM measurements were carried out. After oxidation, all graphite peaks are still visible in the XRD spectrum of both fishbone and parallel fibres. This demonstrates that the graphitic structure of the fibres is unchanged after treatment. Furthermore, the nickel and most of the alumina reflections disappear. This indicates that oxidation in $\mathrm{HNO}_{3} / \mathrm{H}_{2} \mathrm{SO}_{4}$ removes most of the nickel and alumina present between the untreated fibres. Separate experiments revealed that boiling in $\mathrm{HNO}_{3}$ or $\mathrm{HNO}_{3} / \mathrm{H}_{2} \mathrm{SO}_{4}$ for 60 min resulted in a loss of the alumina support of at least 50 and $80 \%$, respectively.

Also, the TEM study of fishbone CNFs did not indicate any changes in the structure of the fibres. Therefore, we conclude that although some of the oxidative treatments affect the texture of parallel carbon nanofibres, the graphitic structure of both fishbone and parallel fibres is maintained after gas or liquid-phase oxidation.

Infrared spectra: The infrared data show that gas-phase oxidation with oxygen and liquid-phase oxidation with $\mathrm{H}_{2} \mathrm{O}_{2}$ are not suitable for creating surface oxides on carbon nanofibres (see also Table 3). Only after considerable burnoff do $\mathrm{C}=\mathrm{O}$-containing surface oxides result from gas-phase treatment. The $\mathrm{H}_{2} \mathrm{O}_{2}$-oxidised fibres show only a weak $\mathrm{C}=\mathrm{O}$ band. It can thus be concluded that $\mathrm{KMnO}_{4} / \mathrm{H}^{+}$or acid treatment is necessary to produce a considerable amount of surface oxides without affecting the macroscopic structure of the fibres. Oxidation in $\mathrm{HNO}_{3} / \mathrm{H}_{2} \mathrm{SO}_{4}$ is the most effective method. Little difference is observed between fishbone and parallel CNFs. Unfortunately, no distinction could be made between carbonyl and carboxy groups. However, we conclude that the presence of carboxy groups is likely, as carboxyic anhydride groups are also present, though their presence was not unambiguously demonstrated by IR spectroscopy.

An important conclusion can be drawn from a comparison of the spectra of untreated and oxidised fibres. We showed that the $\mathrm{CH}_{2} / \mathrm{CH}_{3}$ band at $1454 \mathrm{~cm}^{-1}$ and the aromatic $\mathrm{C}-\mathrm{H}$ minimum at about $875 \mathrm{~cm}^{-1}$ disappear after liquid-phase oxidation, and that the $\mathrm{CH}_{2} / \mathrm{CH}_{3}$ peaks in the $3000-2800 \mathrm{~cm}^{-1}$ region are clearly affected. For the fishbone fibres, a significant decrease in intensity of the $\mathrm{CH}_{2} / \mathrm{CH}_{3}$ bands in the $3000-2800 \mathrm{~cm}^{-1}$ region was observed after treatment with $\mathrm{HNO}_{3} / \mathrm{H}_{2} \mathrm{SO}_{4}$. The parallel fibres show a decrease in intensity 
of these bands after oxidation with $\mathrm{HNO}_{3}$, and total disappearance of these peaks after treatment in $\mathrm{HNO}_{3} /$ $\mathrm{H}_{2} \mathrm{SO}_{4}$. We previously concluded that the bands attributed to $\mathrm{CH}_{2} / \mathrm{CH}_{3}$ vibrations originate from defects in the graphitic structure of the carbon nanofibres. ${ }^{[25]}$ The above results clearly show that the formation of oxygen-containing surface groups occurs at defect sites on the CNFs. With the parallel fibres, all defect carbon-hydrogen bonds are converted into carbon-oxygen bonds. In the fishbone fibres, on the other hand, only part of the defect $\mathrm{CH}$ sites are transformed. We have argued that the graphitic planes of fishbone fibres end in $\mathrm{CH}_{2} / \mathrm{CH}_{3}$ groups. ${ }^{[28]}$ Consequently, due to spacial restrictions, not all carbon-hydrogen bonds can be converted to carbonoxygen bonds. It is also likely that acid treatment creates new defects. On oxidation in air, the carbon-hydrogen bonds do not disappear. In other words, gas-phase oxidation is not initiated on defect sites on carbon nanofibres. Considering that little difference exists between fishbone and parallel CNFs, we conclude that the surface reactivity of both types of fibre is about the same, due to high defect concentrations.

The spectra of fishbone fibres oxidised for $30 \mathrm{~min}$ in $\mathrm{HNO}_{3} /$ $\mathrm{H}_{2} \mathrm{SO}_{4}$ show an increase in the intensity of the $1200 \mathrm{~cm}^{-1}$ absorption, whereas fishbone fibres oxidised for $60 \mathrm{~min}$ do not. In this region of the spectrum $\mathrm{C}-\mathrm{O}$ stretching and $\mathrm{O}-\mathrm{H}$ bending vibrations overlap with the broad $\mathrm{C}-\mathrm{C}$ stretching mode. ${ }^{29]}$ Furthermore, after oxidation for $30 \mathrm{~min}$, only carbonyl or carboxy groups are observed, whereas treatment for 60 min results in the formation of carboxyic anhydride or lactone groups as well. Gustafson et al. ${ }^{[39]}$ stated that during the initial stages of oxidation phenol and carbonyl groups are formed. With continuing oxidation, these groups are converted to carboxy groups. It is also claimed that with the most vigorous oxidizing agents, such as $\mathrm{HNO}_{3} / \mathrm{H}_{2} \mathrm{SO}_{4}$, carboxy groups are preferentially formed. ${ }^{[6,20]} \mathrm{We}$ can therefore conclude that oxidation for $60 \mathrm{~min}$ in $\mathrm{HNO}_{3} / \mathrm{H}_{2} \mathrm{SO}_{4}$ mainly results in the formation of carboxy groups on the surface and that consequently the intensity of the $1200 \mathrm{~cm}^{-1}$ absorption does not increase noticeably. Oxidation for only $30 \mathrm{~min}$, on the other hand, results in a mixture of different surface oxides and thus in an increase in the $1200 \mathrm{~cm}^{-1}$ absorption. The appearance of the $1754 \mathrm{~cm}^{-1}$ band after oxidation for $60 \mathrm{~min}$ is in accordance with the above explanation. Oxidation for a longer period of time in $\mathrm{HNO}_{3} / \mathrm{H}_{2} \mathrm{SO}_{4}$ leads, at the cost of carbonyl groups and other oxides, to a higher concentration of carboxy groups, which can subsequently be converted to carboxyic anhydrides.

In summary, IR spectroscopy showed that oxidation in acid or potassium permanganate is necessary to create surface oxides on carbon nanofibres. Treatment with $\mathrm{HNO}_{3} / \mathrm{H}_{2} \mathrm{SO}_{4}$ appears to be the most effective method. The results show that the formation of oxygen-containing surface groups occurs at defect sites on the carbon nanofibres and that the oxidation proceeds via carbonyl groups and other oxides to carboxy and carboxyic anhydride groups. The surface reactivity of both types of fibre is about the same due to their high defect concentrations.

Thermogravimetric analysis in an inert environment and XPS: The acid- and $\mathrm{KMnO}_{4} / \mathrm{H}^{+}$-treated fibres undoubtedly have carboxy groups on their surface. In addition, carboxyic anhydrides are formed, as well as other CO-evolving surface oxides. Untreated fibres already possess some oxygen-containing surface groups. In the fishbone fibres, some of these are carboxyic anhydride or lactonic groups, because the $\mathrm{CO}_{2}$ is liberated at higher temperatures. Not much difference between fishbone and parallel carbon nanofibres is observed. Comparison of the TGA-MS profiles of fishbone CNFs treated in $\mathrm{HNO}_{3} / \mathrm{H}_{2} \mathrm{SO}_{4}$ for 30 and $60 \mathrm{~min}$ confirm the oxidation mechanism inferred from IR data. Oxidation for 30 min results in the presence of phenolic groups and in less carboxyic anhydride groups than treatment for a longer period of time. Furthermore, as the $\mathrm{CO}$ evolution profiles are different, CO-evolving oxides are present in different ratios on the two kinds of oxidised fibres.

As the weight loss is related to the amount of oxygencontaining surface groups, its value is a measure for the concentration of surface oxides. From Table 2 it is apparent that oxidation in $\mathrm{HNO}_{3} / \mathrm{H}_{2} \mathrm{SO}_{4}$ is the most effective method for creating oxygen groups. With parallel fibres treatment at $500{ }^{\circ} \mathrm{C}$ in air also results in a considerable amount of oxidic surface groups, but more than $50 \%$ of the fibres is lost due to burn-off. Moreover, only the liquid-phase treatments succeed in creating carboxy groups on the surface of the fibres. Although not much difference between parallel and fishbone carbon nanofibres is found, it seems that the parallel fibres are more severely affected by oxidation than the fishbone fibres. However, the difference in surface area should also be taken into account.

The results obtained with TGA-MS correlate well with the IR data. Both techniques indicate that treatment in $\mathrm{HNO}_{3} /$ $\mathrm{H}_{2} \mathrm{SO}_{4}$ is the most effective oxidation treatment. Moreover, both techniques point to the presence of carboxy and carboxyic anhydride groups on the surface of the carbon nanofibres. Because the evolved-gas profiles should only be considered qualitatively, a $\mathrm{CO}_{2} / \mathrm{CO}$ ratio cannot be calculated. It is therefore difficult to quantify the amount of CO-evolving surface oxides present on the nanofibres. The infrared data may indicate that after treatment in $\mathrm{HNO}_{3} / \mathrm{H}_{2} \mathrm{SO}_{4}$ for $60 \mathrm{~min}$ mostly carboxy and carboxyic anhydride groups are formed. However, TGA-MS seems to contradict this finding, as CO is liberated up to high temperatures. The CO could originate solely from carbonyl groups, which vibrate at around $1700 \mathrm{~cm}^{-1}$ and not in the region of $1200 \mathrm{~cm}^{-1}$, but the presence of ether-type oxygen is likely as well.

Although no quantification of the evolved gases is possible, the weight losses give information about the amount of oxygen-containing groups on the carbon nanofibres. If one assumes that $\mathrm{CO}$ and $\mathrm{CO}_{2}$ are evolved in a 1:1 ratio, the surface coverage of oxygen-containing groups would be about 10 groups per square nanometre for the fibres treated for $60 \mathrm{~min}$ in $\mathrm{HNO}_{3} / \mathrm{H}_{2} \mathrm{SO}_{4}\left(7 \%\right.$ weight loss, $\left.120 \mathrm{~m}^{2} \mathrm{~g}^{-1}\right)$. This value is clearly too high for the surface alone. Further examination of the mass spectrometric data showed no loss of $\mathrm{NO}_{x}$ or $\mathrm{SO}_{x}$, originating from $\mathrm{HNO}_{3}$ or $\mathrm{H}_{2} \mathrm{SO}_{4}$, during TGA. Furthermore, up to $\mathrm{m} / \mathrm{z} 100$, additional peaks were only found at $m / z, 12,16$ and 32. The signal-to-noise ratio of these peaks indicates that their intensity is low to very low. The XPS measurements, which did not show any $\mathrm{N}$ or $\mathrm{S}$ on the surface 
of the fibres, confirm the TGA results. Hoogenraad ${ }^{[23]}$ also found a weight loss of about $10 \%$ for parallel fibres grown out of supported Fe particles and treated for $60 \mathrm{~min}$ in nitric acid. Therefore, it seems that the weight losses recorded are relevant and that these are solely due to oxygen-containing groups.

The TGA-MS results are supported by the XPS data, which show high $\mathrm{O} / \mathrm{C}$ ratios on the $\mathrm{CNF}$. The finding that the $\mathrm{C}_{1 \mathrm{~s}}$ peak does not change shape upon oxidation can be explained by taking into account the penetration depth of XPS of about $2 \mathrm{~nm}$ for carbon. Most of the carbon that is detected is situated below the surface of the fibres, and consequently the fraction of carbon that is bonded to oxygen is low, and a change in peak shape cannot be observed. The $\mathrm{O} / \mathrm{C}$ ratios, however, can be converted to a number of oxygen atoms per square metre by standard techniques with a fit program. ${ }^{[40]}$ For the untreated CNFs a value of $1.2 \times 10^{19}$ atoms per square metre (12 atoms per square nanometre) was obtained, and for the oxidised fibres $2.5 \times 10^{19}$ atoms per square metre (25 atoms per square nanometre). Note that the untreated fibres contain about $4 \mathrm{wt} \%$ of $\mathrm{Al}_{2} \mathrm{O}_{3}$ which could already be responsible for $0.7 \times 10^{19}$ oxygen atoms per square metre, but this still leaves an appreciable number of five oxygen atoms per square nanometre. Upon oxidation in $\mathrm{HNO}_{3} / \mathrm{H}_{2} \mathrm{SO}_{4}$, about $80 \%$ of the $\mathrm{Al}_{2} \mathrm{O}_{3}$ is removed. We can therefore estimate that the amount of oxygen exclusively present on the fibres increases by a factor of $4-5$ upon oxidation for $60 \mathrm{~min}$ in $\mathrm{HNO}_{3} / \mathrm{H}_{2} \mathrm{SO}_{4}$. The ratio of the oxygen atoms present before and after oxidation in $\mathrm{HNO}_{3} / \mathrm{H}_{2} \mathrm{SO}_{4}$ agrees well with the results obtained with TGA-MS.

Although the relative change in oxygen content of the untreated and oxidised CNFs is reliable, the absolute values that were obtained are very high. A value of $1.2 \times 10^{19}$ atoms per square metre would already constitute a monolayer of oxygen. However, the number of oxygen atoms per unit surface area was calculated from the XPS data by assuming a perfectly smooth surface of the carbon nanofibres. It was already argued above that the CNFs have a considerable surface roughness and that a surface enhancement factor of four is not unlikely for fishbone fibres. The concentration of oxygen on the surface of the fibres would therefore only be one quarter of the value obtained with XPS. Even then, it can be doubted whether all of the oxygen can be accommodated solely on the surface of the carbon nanofibres.

The increase in the $\mathrm{O} / \mathrm{C}$ ratio after vacuum treatment at $150^{\circ} \mathrm{C}$ for both the untreated and the oxidised fibres is striking. The opposite effect was expected, because the treatment should remove physisorbed water. This effect may be explained by assuming that oxygen-containing groups are present between the graphite sheets of the fibres and that the oxygen moves towards the surface of the fibres under high vacuum. This explanation would support the results obtained with XPS and TGA.

Values for the concentration of surface oxides on activated carbons and graphite wear dust, determined by base titration, are about one group per square nanometre..$^{[2,3,41]}$ However, it is also stated in the literature that chemical titration fails to account for more than $50 \%$ of the oxygen content found by elemental analysis. ${ }^{[2,3,32]}$ Hennig $^{[5]}$ showed that oxygen is only bound at the edge planes of graphite, and that the oxygen content exceeded the number of peripheral carbon atoms significantly. According to Hennig it is likely that part of the oxygen is bound as ether links between adjacent carbon layers, and the graphite lattice would only be slightly contracted by the oxygen atoms. This idea was later confirmed by Boehm, who added that the carbon layers should be puckered at their edges. ${ }^{[2,3]}$ Others mention the possible formation of graphitic oxide at the first external layers of carbon fibres or graphite by $\mathrm{KMnO}_{4} / \mathrm{H}_{2} \mathrm{SO}_{4}$ or anodic oxidation in sulfuric acid or sulfate solutions. ${ }^{[34,42,43]}$ Indeed, many authors found very high oxygen concentrations on carbons. Thermal desorption and nitrogen physisorption data of Figueiredo ${ }^{[35]}$ show that not all the oxygen detected by temperature-programmed desorption can be accommodated on the surface of activated carbon atoms. Several XPS studies revealed that, for strongly oxidised multiwalled carbon nanotubes and parallel carbon nanofibres, up to $15 \%$ of the carbon atoms were bonded to oxygen. ${ }^{[10,20,44]}$ As the probing depth of XPS is about $2 \mathrm{~nm}$ for carbon, five to six carbon layers are analysed by XPS. If the oxide groups were solely present at the surface of the nanomaterials, almost all surface carbon atoms should be bonded to oxygen. This seems highly unlikely, since Mawhinney et al. ${ }^{[22]}$ found that only about $4 \%$ of the carbon atoms of single-walled carbon nanotubes had been oxidised after treatment in $\mathrm{HNO}_{3} / \mathrm{H}_{2} \mathrm{SO}_{4}$.

In summary, weight losses found by TGA-MS are due to the release of $\mathrm{CO}$ and $\mathrm{CO}_{2}$ from oxygen-containing groups on the carbon nanofibres. As the concentration of these groups is too high to be accommodated solely at the surface of the CNFs, it is likely that ether-type oxygen groups are formed between graphite layers that are puckered at their edges. This finding is supported by the XPS data. Infrared spectroscopy showed that the oxidation of carbon nanofibres occurs at defect sites on the surface of the fibres. The very high values for the concentration of oxygen-containing groups on CNFs found with XPS and TGA, which indicate total coverage of the surface with surface oxides, seem to contradict this mechanism. This difference may be explained by assuming that the whole surface of the CNFs is defect-rich. For fishbone fibres this is possible, as the exposed graphitic edges probably do not end in a perfect aromatic ring. For parallel fibres, however, this assumption is highly unlikely, given the orientation of the graphitic planes and the results of TEM studies. ${ }^{[25]}$ With parallel fibres it is more likely that the oxidation occurs at defect sites and that locally at these sites ether-type oxygen is formed between the graphitic planes. This mechanism would also hold for fishbone fibres.

\section{Thermogravimetric analysis in an oxidizing environment:} Because of the identical onset temperature of bulk oxidation, we conclude that the parallel and fishbone CNFs have about the same crystallinity. Once started, oxidation of the parallel fibres proceeds more easily and faster than than that of fishbone $\mathrm{CNFs}$, and a maximum rate of oxidation is reached at lower temperature. As the TGA measurement is a dynamic process, these differences could be due to differences in diffusion of oxygen to the fibres. The parallel fibres are less dense than the fishbone CNFs (see $\mathrm{N}_{2}$ physisorption results), 
and therefore less material is used for TGA. However, because the oxidation process proceeds at high temperature, we think that it is more likely that the intrinsic burning properties of the parallel fibres are different. Once started in a parallel graphene sheet, oxidation should be able to proceed very rapidly along the whole sheet, in contrast to the fishboneoriented graphene sheets.

From a comparison between the untreated and the surfaceoxidised fishbone carbon nanofibres, several conclusions can be drawn. First, as the maximum rate of bulk oxidation is identical, the rate of oxidation is not affected by nickel present in the untreated fibres. Second, as the onset temperatures are different, the bulk oxidation of the untreated fibres is probably preceded by a surface-oxidation step. The $\mathrm{HNO}_{3} /$ $\mathrm{H}_{2} \mathrm{SO}_{4}$-treated fibres are already surface-oxidised and they therefore display a higher onset temperature. Finally, by taking into account that the bulk oxidation proceeds identically for treated and untreated fibres, we can conclude that the number of defect sites on the fishbone CNFs does not change significantly after surface oxidation in $\mathrm{HNO}_{3} / \mathrm{H}_{2} \mathrm{SO}_{4}$. In other words, defects already present on the fibres were surfaceoxidised by the acid mixture. This finding supports the results obtained by IR spectroscopy.

Hydrophobicity: It is well-known that the hydrophobic surface of carbons becomes hydrophilic when covered with oxygen-containing groups. ${ }^{[3]}$ Generally, acidic surface oxides such as carboxy groups are thought to be responsible for the change in affinity for liquids. ${ }^{[4]}$ The untreated CNFs do not show much affinity for hexane, which is too apolar for the fishbone fibres. This could be due to the low concentration of acidic (i.e., $\mathrm{CO}_{2}$-evolving) surface oxides already present on the fibres, as was evident from the TGA-MS results. Hoogenraad ${ }^{[23]}$ also performed test-tube experiments with water/nitrobenzene mixtures and parallel fibres. The untreated fibres were completely located in the organic phase, whereas after treatment in $\mathrm{HNO}_{3}$ the CNFs showed some affinity for water. Although TGA-MS showed that untreated parallel fibres do not bear acidic surface oxides, the results obtained by Hoogenraad indicate that liquids need a certain polarity to wet untreated carbon nanofibres.

The results obtained with the $\mathrm{HNO}_{3}$-treated carbon nanofibres are very interesting. Clearly, the affinity of these treated fibres for water or hexane is influenced by the liquid they first come into contact with. The results might be explained by assuming that there are small hydrophobic and hydrophilic domains on the surface of such treated fibres. Accordingly, the fibres have an affinity both for polar and nonpolar liquids. When the fibres are first wetted with a polar liquid, the nonpolar liquid is repelled, and vice versa. Only after strong oxidation in $\mathrm{HNO}_{3} / \mathrm{H}_{2} \mathrm{SO}_{4}$ is a sufficiently high affinity for water achieved. In this case, the fibres disperse very well in water, independent of the wetting sequence. These results are in accordance with the findings of Esumi et al., ${ }^{[18]}$ who oxidised parallel nanofibres in $\mathrm{HNO}_{3} / \mathrm{H}_{2} \mathrm{SO}_{4}$ and performed sedimentation experiments in water, ethanol and hexane.

The above results are important for the use of carbon nanofibres as a catalyst supports in liquid-phase reactions. By varying the method of surface oxidation, the hydrophobicity of the fibres can be fine-tuned. Consequently, it now becomes possible to design a catalyst support with optimal wetting properties for the desired reaction medium.

\section{Conclusion}

Fishbone and parallel carbon nanofibres were oxidatively treated in the gas- and in the liquid-phase. We found that for the fishbone CNFs the macroscopic structure was not severely affected by any of the treatments used. In contrast, only treatment in $\mathrm{HNO}_{3}$ left the macroscopic structure of the parallel fibres intact. However, the graphitic structure of both types of fibres was maintained after oxidation. Because of the discrepancy between the average diameter of the fibres calculated from $\mathrm{N}_{2}$ physisorption data and that observed with TEM, it is likely that the CNFs have a considerable surface roughness. This is supported by a comparison of TGA-MS and XPS data.

Infrared and TGA-MS measurements revealed that the most effective oxidation method is treatment in a mixture of $\mathrm{HNO}_{3}$ and $\mathrm{H}_{2} \mathrm{SO}_{4}$. This treatment results, amongst others, in the formation of carboxy and carboxyic anhydride groups on the surface of the fibres. Treatment for a longer period of time gives more surface oxides. The high weight losses found with TGA-MS can be solely ascribed to $\mathrm{CO} / \mathrm{CO}_{2}$ evolution from oxygen-containing surface groups. This is supported by XPS data. As the concentration of these groups is too high to be accommodated exclusively at the surface of the CNFs, it is concluded that oxidation also forms ether-type oxygen groups between graphite layers that are puckered at their edges. Little difference was observed between parallel and fishbone CNFs.

The IR results clearly show that the formation of oxygencontaining surface groups occurs at defect sites on the carbon nanofibres. This finding is supported by TGA experiments in an oxidative environment. For the parallel fibres, all defect $\mathrm{CH}$ bonds are converted to $\mathrm{CO}$ bonds, while for the fishbone $\mathrm{CNFs}$, only a fraction of the $\mathrm{CH}$ sites is transformed due to spatial restrictions on the edge surface. Considering that little difference exists between fishbone and parallel CNFs, we conclude that the surface reactivity of both types of fibre is about the same due to high defect densities. From the IR and TGA-MS data it also becomes evident that the surface oxidation of CNFs proceeds via carbonyl groups and other oxides to carboxyic and carboxyic anhydride groups.

From TGA experiments in oxidative environment it can be concluded that parallel and fishbone fibres have about the same crystallinity. Parallel fibres, however, combust faster due to the orientation of the graphene sheets. It was also shown that the bulk oxidation of fishbone fibres is preceded by a surface-oxidation step.

Dispersion experiments with differently treated fishbone carbon nanofibres showed that only $\mathrm{HNO}_{3} / \mathrm{H}_{2} \mathrm{SO}_{4}$-treated fibres have good affinity for water. Although untreated fibres are hydrophobic, a liquid requires a certain polarity to wet untreated fibres. $\mathrm{HNO}_{3}$-oxidised fibres have hydrophilic and hydrophobic domains on their surface. Their wetting behaviour is therefore dependent on the solvent with which they are 
first contacted. The results described above are important for the modification of carbon nanofibres and for the synthesis of carbon-nanofibre-supported catalysts.

\section{Experimental Section}

Growth of carbon nanofibres: Carbon nanofibres of the parallel and the fishbone type were produced by catalytic decomposition of $\mathrm{CO} / \mathrm{H}_{2}$ or $\mathrm{CH}_{4}$, respectively, on $\mathrm{Ni} / \mathrm{Al}_{2} \mathrm{O}_{3}$ catalysts. $\left.{ }^{[23,} 24,45,46\right]$

The $\mathrm{Ni} / \mathrm{Al}_{2} \mathrm{O}_{3}$ catalysts, with 20 or $30 \mathrm{wt} \%$ nickel metal loading, were synthesised by the deposition - precipitation technique. ${ }^{[47]}$ Alumina (Alon$\mathrm{C}$, Degussa) was suspended in an acidified aqueous solution of nickel nitrate (Acros, 99\%), and dilute ammonia was injected over $2 \mathrm{~h}$ at room temperature with vigorous stirring until the $\mathrm{pH}$ had reached 8.5. After stirring overnight, the suspension was filtered, washed and dried at $120^{\circ} \mathrm{C}$. Finally, the catalyst was calcined at $600{ }^{\circ} \mathrm{C}$ in stagnant air for $3 \mathrm{~h}$.

Parallel carbon nanofibres were synthesised in small quantities in a fully automated microflow system. Fishbone carbon nanofibres were grown on a larger scale in a manually operated setup. Therefore, somewhat different synthesis conditions were employed.

For the growth of parallel carbon nanofibres, the $20 \mathrm{wt} \% \mathrm{Ni} / \mathrm{Al}_{2} \mathrm{O}_{3}$ catalyst $\left(100 \mathrm{mg}\right.$ ) was reduced at $700{ }^{\circ} \mathrm{C}$ in $20 \% \mathrm{H}_{2} / \mathrm{Ar}$ (flow rate $100 \mathrm{~mL} \mathrm{~min}^{-1}$ ) in the microflow reactor for $2 \mathrm{~h}$. After reduction, the temperature was decreased to $600{ }^{\circ} \mathrm{C}$, and synthesis gas $\left(20 \% \mathrm{CO}\right.$ and $7 \% \mathrm{H}_{2}$ in Ar, flow rate $100 \mathrm{~mL} \mathrm{~min}^{-1}$ ) was passed through the reactor for $10 \mathrm{~h}$. After reaction, about $0.5 \mathrm{~g}$ of parallel CNFs was collected.

For the production of fishbone $\mathrm{CNFs}$, the $30 \mathrm{wt} \% \mathrm{Ni} / \mathrm{Al}_{2} \mathrm{O}_{3}$ catalyst $(0.5 \mathrm{~g})$ was reduced at $600^{\circ} \mathrm{C}$ in $14 \% \mathrm{H}_{2} / \mathrm{N}_{2}$ (flow rate $350 \mathrm{~mL} \mathrm{~min}^{-1}$ ) in a vertical tubular reactor (diameter $3 \mathrm{~cm}$ ) for $2 \mathrm{~h}$. Subsequently, the temperature was decreased to $570{ }^{\circ} \mathrm{C}$, and methane $\left(50 \%\right.$ in $\mathrm{N}_{2}$, flow rate $\left.450 \mathrm{~mL} \mathrm{~min}^{-1}\right)$ was passed through the catalyst bed for $6.5 \mathrm{~h}$. The yield of fibres was approximately $12 \mathrm{~g}$.

The synthesis of the parallel and fishbone CNFs was confirmed by highresolution TEM. ${ }^{[28]}$

Oxidation of carbon nanofibres: Fishbone and parallel carbon nanofibres were subjected to several gas- and liquid-phase oxidative treatments.

Fishbone CNFs were heated in a stream of $20 \% \mathrm{O}_{2} / \mathrm{He}$ at $300{ }^{\circ} \mathrm{C}$ for $72 \mathrm{~h}$, which resulted in $6 \%$ burn-off. Parallel fibres were oxidised in stagnant air at $500{ }^{\circ} \mathrm{C}$ for $1 \mathrm{~h}$; burn-off was greater than $50 \%$.

Both fishbone and parallel nanofibres were oxidised in refluxing concentrated nitric acid and in a 1/1 mixture of concentrated nitric and sulfuric acid $\left(\mathrm{HNO}_{3}\right.$, Lamers \& Pleuger, $65 \%$, pure; $\mathrm{H}_{2} \mathrm{SO}_{4}$, Merck, $95-97 \%$, p.a.). CNFs (3-10 g) were boiled in $\mathrm{HNO}_{3}(40 \mathrm{~mL})$ or $\mathrm{HNO}_{3} / \mathrm{H}_{2} \mathrm{SO}_{4}(80 \mathrm{~mL})$ for 30 or $60 \mathrm{~min}$. After cooling and dilution with demineralised water, the suspensions were filtered over a Teflon membrane filter with a pore diameter of $0.2 \mu \mathrm{m}$, washed with water until the washings showed no significant acidity and dried at $120^{\circ} \mathrm{C}$ for $16 \mathrm{~h}$. Fishbone fibres were also oxidised by boiling for $2 \mathrm{~h}$ in $30 \% \mathrm{H}_{2} \mathrm{O}_{2}$ (Merck, $30 \%$, medical extra pure, stabilised) or in $0.5 \mathrm{M} \mathrm{KMnO}_{4}$ (Merck, cryst. extra pure) in $5 \% \mathrm{H}_{2} \mathrm{SO}_{4}$. After the permanganate treatment, the fibres were immersed in concentrated hydrochloric acid to remove $\mathrm{MnO}_{2}$. The oxidised fibres were then thoroughly washed and dried at $120^{\circ} \mathrm{C}$ for $16 \mathrm{~h}$. For the fibres treated with acid or peroxide, material losses were less than $5 \%$, whereas the permanganate oxidation procedure resulted in a $15 \%$ loss of CNFs.

Characterisation of carbon nanofibres: Both untreated and oxidised nanofibres was characterised by nitrogen physisorption, X-ray diffraction (XRD), scanning electron microscopy (SEM), transmission electron microscopy (TEM), infrared spectroscopy (IR), thermogravimetric analysis (TGA) and X-ray photoelectron spectroscopy (XPS).

$\mathrm{CNF}$ samples were degassed at $120^{\circ} \mathrm{C}$ in vacuum for at least $16 \mathrm{~h}$, and nitrogen adsorption-desorption isotherms were measured at $77 \mathrm{~K}$ on a Micromeretics ASAP 2400 apparatus. Specific surface areas and pore volumes were calculated from the data obtained.

SEM micrographs were obtained on a Philips XL30FEG microscope at an accelerating voltage of $20 \mathrm{kV}$. TEM samples were prepared by dispersing ground nanofibres in ethanol with ultrasound and drying a drop on a copper grid covered by a holey carbon film. They were imaged in a Philips EM-420 electron microscope operated at an accelerating voltage of $120 \mathrm{kV}$.

Powder XRD measurements were performed on an Enraf-Nonius X-ray diffraction system equipped with a curved position-sensitive INEL detector operating up to a width of $2 \theta=120^{\circ}$ with $\mathrm{Co}_{\mathrm{K} \alpha}$ radiation $(\lambda=1.78897 \AA)$. Transmission IR data were recorded on a Perkin Elmer 2000 spectrometer equipped with an air dryer for removal of water vapour and carbon dioxide. One hundred scans were co-added with a resolution of $8 \mathrm{~cm}^{-1}$ and a boxcar apodisation. Samples were prepared by thoroughly mixing a small amount of ground nanofibres with pre-dried $\mathrm{KBr}$. Tablets were pressed at $4 \mathrm{tcm}^{-2}$ in vacuum for $2 \mathrm{~min}$. The concentrations of the nanofibres ranged from 0.1 to $1 \%$ o $(\mathrm{m} / \mathrm{m})$. All spectra were baseline-corrected.

TGA was carried out on a Netzsch STA-429 thermobalance. The gases evolved during analysis were monitored by a Fisons Thermolab quadropole mass spectrometer, through a capillary situated directly above the sample cup. Samples $(20-100 \mathrm{mg})$ were heated in $\mathrm{Ar}\left(60 \mathrm{~mL} \mathrm{~min}^{-1}\right)$ or $20 \% \mathrm{O}_{2} / \mathrm{Ar}$ at a rate of $300 \mathrm{Kh}^{-1}$ to $850^{\circ} \mathrm{C}$.

The XPS data were obtained with a Vacuum Generators XPS system, with a CLAM-2 hemispherical analyser for electron detection. Nonmonochromatic $\mathrm{Al}_{\mathrm{K} \alpha} \mathrm{X}$-ray radiation was obtained by using an anode current of $20 \mathrm{~mA}$ at $10 \mathrm{keV}$. The pass energy of the analyser was set at $20 \mathrm{eV}$.

\section{Acknowledgements}

The authors acknowledge Prof. Dr. J. H. van der Maas of the Department of Vibrational Spectroscopy, Utrecht University, for discussions on the IR data. We also thank A. Broersma for recording the TGA data. This work was supported by the Netherlands Organisation for Scientific Research (NWO).

[1] K. P. de Jong, J. W. Geus, Catal. Rev.-Sci. Eng. 2000, 42(4), 481-510.

[2] H. P. Boehm, Adv. Catal. 1966, 16, 179-274.

[3] H. P. Boehm, Carbon 1994, 32(5), 759-769.

[4] S. S. Barton, M. J. B. Evans, E. Halliop, J. A. F. MacDonald, Carbon 1997, 35(9), $1361-1366$.

[5] G. R. Hennig, Proc. 5th Conf. Carbon, Vol. I, Pergamon Press, Oxford, 1962 , p. 143.

[6] J. R. Anderson, Structure of Metallic Catalysts, Academic Press, London, 1975, p. 81.

[7] C. Moreno-Castilla, M. A. Ferro-García, J. P. Joly, I. Bautista-Toledo, F. Carrasco-Marín, J. Rivera-Utrilla, Langmuir 1995, 11, 4386-4392.

[8] C. Prado-Burguete, A. Linares-Solano, F. Rodríguez-Reinoso, C. Salinas-Martínez de Lecea, J. Catal. 1989, 115, 98-106.

[9] T. W. Ebbesen, P. M. Ajayan, H. Hiura, K. Tanigaki, Nature 1994, 367, 519.

[10] H. Hiura, T. W. Ebbesen, K. Tanigaki, Adv. Mater. 1995, 7, 275-276.

[11] R. M. Lago, S. C. Tsang, K. L.Lu, Y. K. Chen, M. L. H. Green, J. Chem. Soc. Chem. Commun. 1995, 1355-1356.

[12] J. Liu, A. G. Rinzler, H. Dai, J. H. Hafner, R. K. Bradley, P. J. Boul, A. Lu, T. Iverson, K. Shelimov, C. B. Huffman, F. Rodriguez-Macias, Y.S. Shon, T. R. Lee, D. T. Colbert, R. E. Smalley, Science 1998, 280, $1253-1256$.

[13] S. C. Tsang, Y. K. Chen, P. J. F. Harris, M. L. H. Green, Nature 1994, $372,159-162$.

[14] K. C. Hwang, J. Chem. Soc. Chem. Commun. 1995, 173-174.

[15] J. Cook, J. Sloan, M. L. H. Green, Chem. Ind. 1996, 600-603.

[16] M. A. Hamon, J. Chen, H. Hu, Y. Chen, M. E. Itkis, A. M. Rao, P. C. Eklund, R. C. Haddon, Adv. Mater. 1999, 11, 834-840.

[17] A. Kuznetsova, D. B. Mawhinney, V. Naumenko, J. T. Yates, J. Liu, R. E. Smalley, Chem. Phys. Lett. 2000, 321, 292-296.

[18] K. Esumi, M. Ishigami, A. Nakajima, K. Sawada, H. Honda, Carbon 1996, 34, 279-281

[19] M. S. P. Shaffer, X. Fan, A. H. Windle, Carbon 1998, 36(11), 1603 1612.

[20] H. Ago, T. Kugler, F. Cacialli, W. R. Salaneck, M. S. P. Shaffer, A. H. Windle, R. H. Friend, J. Phys. Chem. B 1999, 103, 8116-8121.

[21] Z. Jia, Z. Wang, J. Liang, B. Wei, D. Wu, Carbon 1999, 37, 903-906. 
[22] D. B. Mawhinney, V. Naumenko, A. Kuznetsova, J. T. Yates, J. Liu, R. E. Smalley, Chem. Phys. Lett. 2000, 324, 213-216.

[23] M. S. Hoogenraad, PhD Thesis, Utrecht University (NL), 1995.

[24] M. S. Hoogenraad, M. F. Onwezen, A. J. van Dillen, J. W. Geus, Stud. Surf. Sci. Catal. 1995, 101, 1331-1339.

[25] T. G. Ros, A. J. van Dillen, J. W. Geus, D. C. Koningsberger, ChemPhysChem 2002, 3, 209-214.

[26] W. M. Prest, R. A. Mosher in Colloids and Surfaces in Reprographic Technology (Eds.: M. Hair, M. Croucher), ACS Symposium Series, Vol. 200, ACS, Washington, 1982, pp. 225-247.

[27] K. Nakamoto, Infrared and Raman Spectra of Inorganic and Coordination Compounds, 4th ed., Wiley, New York, 1986, p. 124.

[28] U. Zielke, K. J. Hüttinger, W. P. Hoffman, Carbon 1996, 34, 983 - 998.

[29] P. Painter, M. Starsinic, M. Coleman in Fourier Transform Infrared Spectroscopy, Applications to Chemical Systems, Vol. 4 (Eds.: J. R. Ferraro, L. J. Basile), Academic Press, Orlando, 1985, 169-241.

[30] D. B. Mawhinney, V. Naumenko, A. Kuznetsova, J. T. Yates, J. Am. Chem. Soc. 2000, 122, 2383-2384.

[31] J. Chen, M. A. Hamon, H. Hu, Y. Chen, A. M. Rao, P. C. Eklund, R. C. Haddon, Science 1998, 282, 95-98.

[32] J. L. Figueiredo, M. F. R. Pereira, M. M. A. Freitas, J. J. M. Órfão, Carbon 1999, 37, 1379-1389.

[33] V. Gómez-Serrano, F. Piriz-Almeida, C. J. Durán-Valle, J. PastorVillegas, Carbon 1999, 37, 1517-1528.

[34] P. Ehrburger in Carbon Fibers Filaments and Composites (Eds.: J. L. Figueiredo, C. A. Bernardo, R. T. K. Baker, K. J. Hüttinger), NATO ASI series C, Vol. 177, Kluwer Academic Publishers, Dordrecht, 1990, pp. $147-161$.
[35] K. Miura, T. Morimoto, Langmuir 1994, 10, 807-811.

[36] CRC Handbook of Chemistry and Physics, 69th ed. (Eds.: R. C. Weast, M. J. Astle, W. H. Beyer), CRC Press, Boca Raton, 1988, p. B-82.

[37] V. B. Fenelonov, L. B. Avdeeva, V. I. Zheivot, L. G. Okkel', O. V. Goncharova, L. G. Pimneva, Kinet. Catal. (Engl. Trans.) 1993, 34(3), $483-487$.

[38] Sh. K. Shaikhutdinov, Kinet. Catal. (Engl. Trans.) 1995, 36(4), 549557.

[39] B.-W. Chun, C. R. Davis, Q. He, R. R. Gustafson, Carbon 1992, 30 , $177-187$.

[40] O. L. J. Gijzeman, unpublished results.

[41] T. Kuretzki, PhD Thesis, Ludwig-Maximilian University München, Germany, 1993.

[42] A. D. Jannakoudakis, P. D. Jannakoudakis, E. Theodoriou, J. Appl. Electrochem. 1990, 20, 619-624.

[43] J. W. Peckett, P. Trens, R. D. Gougeon, A. Pöppl, R. K. Harris, M. J. Hudson, Carbon 2000, 38, 345-353.

[44] C. Niu, E. K. Sichel, R. Hoch, D. Moy, H. Tennent, Appl. Phys. Lett. 1997, 70, 1480-1482.

[45] J. W. Geus, M. S. Hoogenraad, A. J. van Dillen in Synthesis and Properties of Advanced Catalytic Materials (Eds.: E. Iglesia, P. W. Lednor, D. A. Nagaki, L. T. Thompson), Materials Research Society Pittsburgh, Pittsburgh, 1995, pp. 87-98.

[46] W. Teunissen, PhD Thesis, Utrecht University (NL), 2000.

[47] J. W.Geus, Stud. Surf. Sci. Catal. 1983, 16, 1-33.

Received: July 3, 2001 [F3390] 